\title{
Acquired Factor XIII Deficiency
}

National Cancer Institute

\section{Source}

National Cancer Institute. Acquired Factor XIII Deficiency. NCI Thesaurus. Code C131629.

An acquired coagulation disorder characterized by the partial or complete absence of factor XIII activity in the blood. 